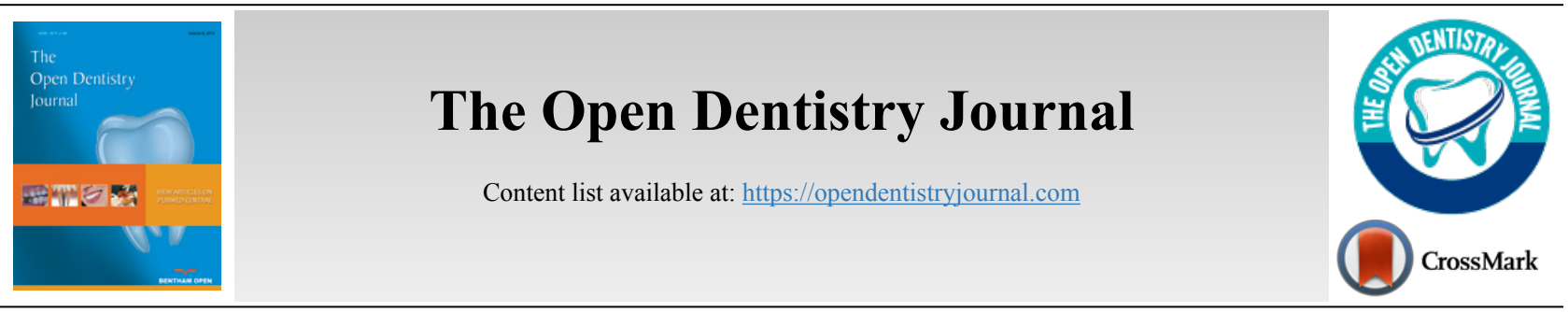

RESEARCH ARTICLE

\title{
Oral Health Knowledge, Behaviour, and Access to Dental Care in Visually Impaired Individuals in Jordan: A Case-Control Study
}

\author{
Sabha Alshatrat ${ }^{1 *}(\mathbb{D})$, Isra AL Bakri ${ }^{1}$, Wael AL Omari ${ }^{2,3}$ and Abedelmalek Tabnjh ${ }^{1}(\mathbb{C}$ \\ ${ }^{1}$ Department of Applied Dental Sciences, Jordan University of Science and Technology, Irbid, Jordan \\ ${ }^{2}$ Department of Prosthodontics, Faculty of Dentistry, Jordan University of Science and Technology, Irbid, Jordan \\ ${ }^{3}$ Prosthetic and Restorative sciences Department, College of Dentistry, King Saud bin Abdulaziz University for Health Sciences, Riyadh, Saudi Arabia
}

\begin{abstract}
:
Aim:

The study aimed to assess oral health knowledge, dental behaviors, and use of dental services in individuals with vision impairment in Jordan and identify barriers that affect their access to dental care in comparison with individuals without vision impairment.

\section{Materials and Methods:}

A case-control study was carried out among 399 parents/caregivers of individuals with vision impairment and individuals without vision impairment, which involved the completion of a self-designed questionnaire. A closed-ended, validated self-designed questionnaire was distributed. The questionnaire included questions addressing participants' oral health knowledge, oral health behaviour, dental service use and barriers to accessing dental care. Data were analyzed using SPSS ${ }^{\circledR}$ software Version 22 with a 0.05 level of significance. A Chi-square test and contingency-table analysis were performed on the data.
\end{abstract}

\section{Results:}

Individuals with vision impairment in Jordan were significantly less knowledgeable about different oral health aspects than sighted counterparts. In addition, individuals with vision impairment used toothbrush, dental floss, and mouth rinse less frequently. They also visited dentists less regularly and mostly when only feeling pain. Limited access to dental services was observed among individuals with vision impairment compared to sighted individuals. Barriers, including embarrassment (22\%), lack of knowledge of how to treat people with disabilities among dentists (12.5\%), and inadequate facilities $(13.7 \%)$, were significantly $(\mathrm{P}<0.05)$ more likely to be reported by visually impaired participants than the controls.

\section{Conclusion:}

Visually impaired individuals and their families should be given appropriate education about oral health care by oral health professionals to reduce the risk of having dental problems and oral disease and enhance their quality of life. Furthermore, recognizing the challenges in accessing dental care for this population could help oral health professionals to minimize these difficulties.

Keywords: Oral health knowledge, Vision impairment, Access to care, Chi-square test, Self-designed questionnaire, Cronbach's alpha.

\begin{tabular}{l|l|l|l} 
Article History & Received: November 10, 2020 & Revised: January 2, 2021 & Accepted: January 7, 2021
\end{tabular}

\section{INTRODUCTION}

Research has shown that individuals with disabilities are more likely to have poorer oral health than individuals without disabilities [1,2].Specifically, studies have shown that people with visual disorders have poorer oral hygiene, higher caries incidence, various levels of periodontal diseases and less access to dental care compared to individuals without vision

\footnotetext{
* Address correspondence to this author at the Department of Applied Dental Sciences, Jordan University of Science and Technology, Irbid, Jordan;

E-mail: smalshatrat@just.edu.jo
}

impairment. The higher prevalence of dental caries in visually impaired people refers to inadequate plaque removal which may be attributed to lack of cleaning habits, healthy diet, eating pattern, physical limitations, medication and attitudes of parents and caregivers [3 - 7]. Visual disorders affect oral health due to physical, social, or informational barriers related to impairment, medical condition, or a lack of customized information [8]. People with visual disorders cannot visualize plaque on their teeth surfaces which makes it difficult for them to understand the importance of oral hygiene, which results in 
the progression of dental caries as well as periodontal diseases [5].

There are many barriers to the provision of dental care for visually impaired individuals. The attitude of the patients, caretakers, and providers is still the main barrier [9]. The other barriers include difficulties in transportation, inadequate resources or financial considerations, lack of services, lack of social awareness, or lack of education and training of service provider's difficulties [9]. So, there is a need to create an awareness about oral care and plaque control to reduce the prevalence of oral diseases among visually impaired individuals [5]. Attitude modifications for visually impaired individuals, their parents and caregivers are one of the most important ways to improve oral health for those patients. Diet counseling, dental health education and preventive procedures, plaque removal instruction, frequency and timing of oral hygiene procedures, dental health education, and audio-tactile performance techniques are other aspects of improving oral health status for individuals with visual impairment [8].

In Jordan, the prevalence of blindness is about $0.54 \%$, and it is almost equally distributed between males and females [10]. The main causes of low vision and blindness in Jordan are cataracts, refractive error, diabetic retinopathy, amblyopia, corneal central opacity and trauma [10].

Since individuals with visual impairment are at higher risk for oral diseases, routine dental care is important to maintain optimal oral health. Yet, no studies were conducted in Jordan addressing the dental knowledge, oral health-related behaviour, challenges, and barriers faced by individuals with visual impairment. In fact, no information is available about oral hygiene practices among this vulnerable group.

This study aims to fill the gap in oral health information in individuals with visual impairment in Jordan. Therefore, the main objective of this study is to assess the knowledge, behaviours, and identify perceived barriers to accessing dental care among individuals with visual impairment in Jordan compared to individuals without visual impairment.

\section{MATERIALS AND METHODS}

Our research was conducted in full accordance with the World Medical Association Declaration of Helsinki [11]. A self-designed questionnaire was formulated in the Arabic language, the official Jordanian language. The content validity of the self-designed questionnaire was established by a panel of applied medical sciences faculty at JUST and the Average Congruency Percentage (ACP) was calculated. Acceptable application for this questionnaire in this study was indicated by the ACP score of the two experts, which was equal to 0.92 . Test-retest reliability was achieved by administering the questionnaire twice to the same individuals $(n=10)$. To test the internal reliability of the questionnaire, Cronbach's alpha was used. Cronbach's alpha coefficient was equal to 0.75 , indicating the items have acceptable internal consistency. The questionnaire was pilot tested using 10 parents/caregivers of individuals with visual impairment to answer the questionnaire on behalf of their children with visual impairment, then to provide feedback on time, clarity of wording, and format. The pilot study participants were not included in the final study.

\subsection{Study Population}

Convenience sampling was used for this study from a list of special care centers associated with vision impairment which was obtained from the Ministry of Social Development and Ministry of Education [12, 13]. The sample was recruited from the centers/schools who agreed to participate in the study. From August 2018 to February 2019, centers and schools associated with vision impairment in Jordan were visited during normal working hours. The centers and the schools were asked to distribute the questionnaire to the parent/caregiver of their members.

\subsection{Study Questionnaire}

A paper format of the questionnaire with a cover letter explaining the study was available for the parent/caregiver to answer the questions on the respondent's behalf provided by the teacher in the parent-teacher communication folder and filled in at home. This was done to increase the level of comfort among individuals with vision impairment while answering the questions since they tend to feel more socially isolated compared to sighted individuals $[14,15]$.

The control group was composed of individuals without visual impairment from the same geographic area of the centers. The control group was selected from the same areas where the cases studied were enrolled. The questionnaire consisted of questions assessing socio-demographic characteristics, questions assessing participant's oral health knowledge, questions assessing participant's oral health behaviour, questions assessing participant's dental service use and barriers to access to dental care.

\subsection{Statistical Analysis}

The data were anonymized and de-identified prior to analysis. All data was reported in group form. Responses were coded and analysed using SPSS Version 22 (IBM Corp., Armonk, NY, USA), with a 0.05 level of significance. Completed questionnaires were considered as a proxy for consent to participate in the study. A Chi-square test and contingency-table analysis were performed on the data.

\section{RESULTS}

A descriptive analysis of univariate distributions was obtained for each of the 20 questionnaire items. Since not all respondents answered each question, the denominator used to calculate the proportions was the total number of non-missing values. The final sample size of the study was $\mathrm{N}=168$ with vision impairment and $\mathrm{N}=231$ for control with a response rate of $74 \%$ for the total sample. The mean age of the overall sample size was 17.9 for visually impaired participants and 18.3 for the control group with no significant difference ( $>0.05$ ) between male to female ratio in the study population. Yet the educational level showed a significant difference $(p=0.000)$. Descriptive characteristics of the sample have been presented in Table $\mathbf{1}$. 
Table 1. Socio-demographic characteristic of individuals with vision impairment and the control group.

\begin{tabular}{|c|c|c|c|c|c|c|}
\hline \multirow{2}{*}{\multicolumn{2}{|c|}{$\begin{array}{c}\text { Characteristics } \\
\text { Gender }\end{array}$}} & \multicolumn{2}{|c|}{ Visually Impaired N (\%) } & \multicolumn{2}{|c|}{ Control N (\%) } & \multirow{2}{*}{$\frac{P \text {-value }}{-}$} \\
\hline & & & & & & \\
\hline- & Male & 93 & $(55.4 \%)$ & 141 & $(61.0 \%)$ & \multirow[t]{2}{*}{.260} \\
\hline- & Female & 75 & $(44.6 \%)$ & 90 & $(39.0 \%)$ & \\
\hline \multicolumn{2}{|c|}{ Education } & \multicolumn{4}{|c|}{-} & - \\
\hline- & Elementary & 62 & $36.9 \%$ & 134 & $(58.0 \%)$ & \multirow[t]{6}{*}{$.000 *$} \\
\hline- & Middle school & 52 & $31.0 \%$ & 21 & $(9.1 \%)$ & \\
\hline- & High school & 34 & $20.2 \%$ & 14 & $(6.1 \%)$ & \\
\hline- & Collage & 3 & $1.2 \%$ & 12 & $(5.2 \%)$ & \\
\hline- & University & 8 & $4.8 \%$ & 42 & $(18.2 \%)$ & \\
\hline- & Graduates & 9 & $5.4 \%$ & 8 & $(3.5 \%)$ & \\
\hline \multicolumn{2}{|c|}{ Income (Jordanian Dinar JD) } & \multicolumn{4}{|c|}{-} & - \\
\hline- & $<250$ & 97 & $(57.7 \%)$ & 4 & $(1.7 \%)$ & \multirow[t]{5}{*}{$.000 *$} \\
\hline- & $250-500$ & 17 & $(10.1 \%)$ & 20 & $(8.7 \%)$ & \\
\hline- & $501-1000$ & 4 & $(2.4 \%)$ & 35 & $(15.2 \%)$ & \\
\hline- & $>1000$ & 0 & $(0.0 \%)$ & 23 & $(10.0 \%)$ & \\
\hline- & Does not work & 50 & $(29.8 \%)$ & 149 & $(64.5 \%)$ & \\
\hline \multicolumn{7}{|c|}{ Insurance } \\
\hline- & Yes & 111 & $(65.5 \%)$ & 167 & $(72.3 \%)$ & \multirow[t]{2}{*}{.195} \\
\hline- & No & 57 & $(33.9 \%)$ & 64 & $(27.7 \%)$ & \\
\hline
\end{tabular}

*Significant result, $(p<.05)$. Chi-square test.

With respect to the response of the participants to oral health knowledge, a significant lack of knowledge was detected among visually impaired individuals compared to the control group in most of the items. However, no significant difference was found in the knowledge regarding the bacteria as a cause of tooth decay $(\mathrm{p}=0.82)$. Table 2 illustrates the 13 items assessing the knowledge level among participants.

Table 2. Oral health knowledge among visually impaired individuals compared to the control group.

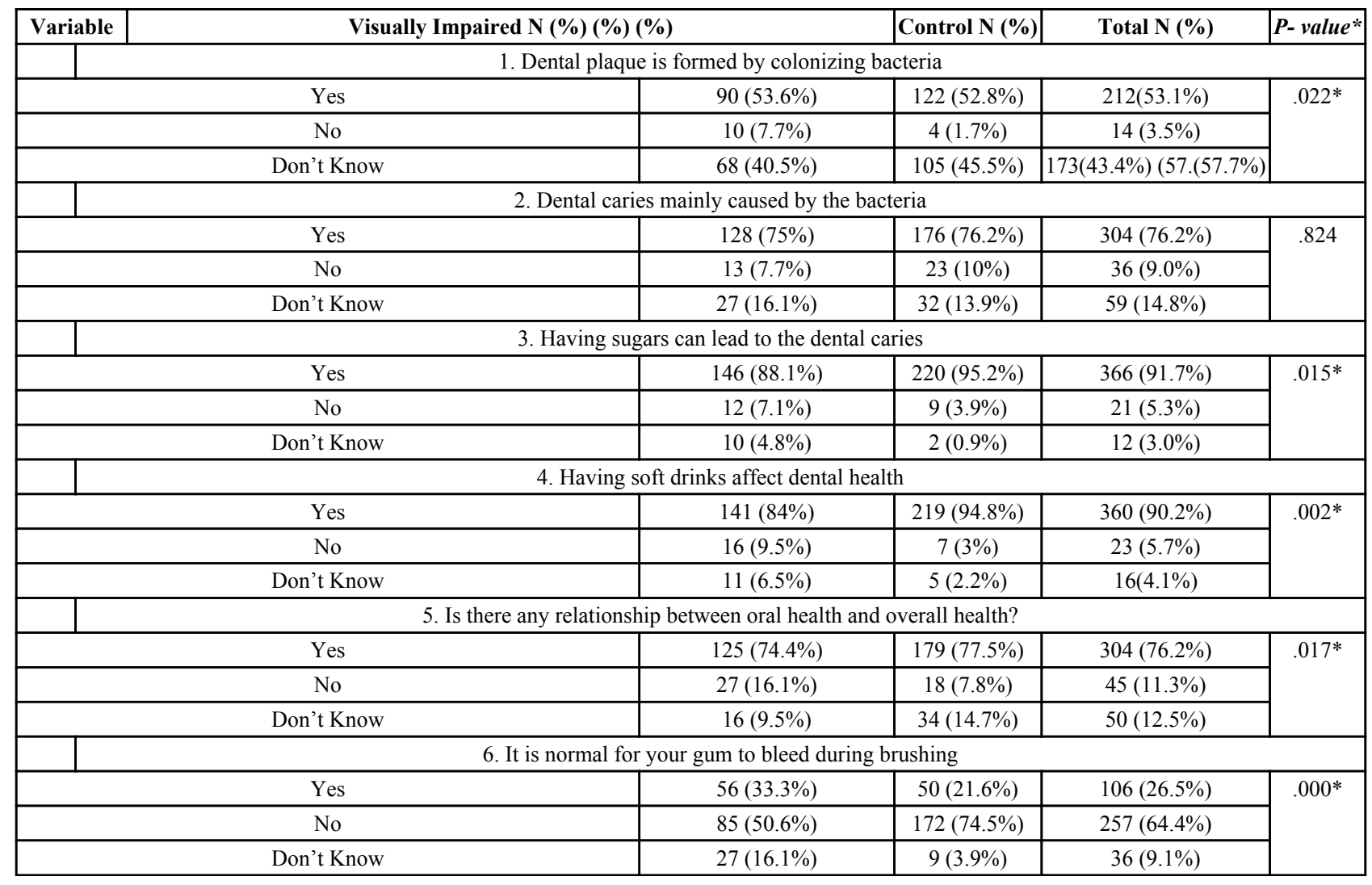


(Table 2) contd.....

\begin{tabular}{|c|c|c|c|c|c|}
\hline Variable & \multicolumn{2}{|c|}{ Visually Impaired N (\%) (\%) (\%) } & Control N (\%) & Total N (\%) & P-value* \\
\hline \multicolumn{6}{|c|}{ 7. It is normal for your gum to be red } \\
\hline & Yes & $23(13.6 \%)$ & $81(35.1 \%)$ & $104(26.1 \%)$ & \multirow[t]{3}{*}{$.000^{*}$} \\
\hline & No & $134(79.8 \%)$ & $136(58.9 \%)$ & $270(67.7 \%)$ & \\
\hline & Don't Know & $11(6.5 \%)$ & $14(6.1 \%)$ & $25(6.2 \%)$ & \\
\hline \multicolumn{6}{|c|}{ 8. It is normal for your gum to be swelling } \\
\hline & Yes & $139(82.7 \%)$ & $6(2.6 \%)$ & $145(36.3 \%)$ & \multirow[t]{3}{*}{$.000^{*}$} \\
\hline & No & $22(13.1 \%)$ & $219(94.8 \%)$ & $241(60.4 \%)$ & \\
\hline & Don't Know & $6(3.6 \%)$ & $7(2.6 \%)$ & $13(3.3 \%)$ & \\
\hline \multicolumn{6}{|c|}{ 9. Brushing teeth on a regular basis protects your teeth } \\
\hline & Yes & $124(73.8 \%)$ & $222(96.1 \%)$ & $346(86.7 \%)$ & \multirow[t]{3}{*}{$.000^{*}$} \\
\hline & No & $35(20.8 \%)$ & $8(3.5 \%)$ & $43(10.8 \%)$ & \\
\hline & Don't Know & $9(5.4 \%)$ & $1(0.4 \%)$ & $10(2.5 \%)$ & \\
\hline \multicolumn{6}{|c|}{ 10. You need to visit a dentist only when you have a toothache } \\
\hline & Yes & $88(52.4 \%)$ & $59(25.5 \%)$ & $147(36.8 \%)$ & \multirow[t]{3}{*}{$.000^{*}$} \\
\hline & No & $37(22.0 \%)$ & $167(72.3 \%)$ & $204(51.1 \%)$ & \\
\hline & Don't Know & $42(25.1 \%)$ & $6(2.2 \%)$ & $48(12.1 \%)$ & \\
\hline \multicolumn{6}{|c|}{ 11. You need a hard toothbrush to clean your teeth } \\
\hline & Yes & $120(71.4 \%)$ & $47(20.3 \%)$ & $167(41.9 \%)$ & \multirow[t]{3}{*}{$.000 *$} \\
\hline & No & $32(19 \%)$ & $178(77.1 \%)$ & $210(52.6 \%)$ & \\
\hline & Don't Know & $16(9.5 \%)$ & $6(2.6 \%)$ & $22(5.5 \%)$ & \\
\hline \multicolumn{6}{|c|}{ 12. Dental floss is necessary to keep your teeth clean } \\
\hline & Yes & $135(80.4 \%)$ & $164(71.8 \%)$ & $299(74.9 \%)$ & \multirow[t]{3}{*}{$.006^{*}$} \\
\hline & No & $21(12.5 \%)$ & $25(10.8 \%)$ & $46(11.5 \%)$ & \\
\hline & Don't Know & $12(7.1 \%)$ & $42(18.2 \%)$ & $54(13.6 \%)$ & \\
\hline \multicolumn{6}{|c|}{ 13. Caries can lead to loss of natural teeth } \\
\hline & Yes & $113(67.3 \%)$ & $222(96.1 \%)$ & $335(83.9 \%)$ & \multirow[t]{3}{*}{$.000 *$} \\
\hline & No & $14(8.3 \%)$ & $6(2.6 \%)$ & $20(5.0 \%)$ & \\
\hline & Don't Know & $41(24.4 \%)$ & $3(1.3 \%)$ & $44(11.1 \%)$ & \\
\hline
\end{tabular}

*Significant result, $P<.05$, Chi-square test.

The participants' dental behavior indicated that there were significantly fewer individuals with vision impairment who brushed their teeth once or twice daily (77.4\%), compared to the control group $(93.5 \%)(\mathrm{P}<0.01)$. An significant difference $(\mathrm{P}<0.05)$ was also found in the frequency of the use of dental floss, mouth rinse and fluoridated toothpaste. However, both visually impaired and control participants were found to consume sweets in a relatively similar routine. Table $\mathbf{3}$ demonstrates the response of the participants to dental behavior questions.

Table 3. Dental behavior among visually impaired individuals compared to the control group.

\begin{tabular}{|c|c|c|c|c|}
\hline Variable & Visually Impaired N (\%) & Control N (\%) & Total N (\%) & $P$-Value \\
\hline $\begin{array}{l}\text { How often do you brush? } \\
\text { Once or more } \\
\text { Occasionally or none }\end{array}$ & $\begin{array}{c}130(77.4 \%) \\
38(22.6 \%)\end{array}$ & $\begin{array}{c}216(93.5 \%) \\
15(6.5 \%)\end{array}$ & $\begin{array}{l}346(86.7 \%) \\
53(13.3 \%)\end{array}$ & $.000^{*}$ \\
\hline $\begin{array}{c}\text { Ability to brush } \\
\text { Completely without help } \\
\text { With some help } \\
\text { Completely with help }\end{array}$ & $\begin{array}{l}115(68.5 \%) \\
36(21.4 \%) \\
17(10.1 \%)\end{array}$ & $\begin{array}{l}231(100 \%) \\
0(0 \%) \\
0(0 \%)\end{array}$ & $\begin{array}{l}346(86.7 \%) \\
36(9.0 \%) \\
17(4.3 \%)\end{array}$ & $.000^{*}$ \\
\hline $\begin{array}{c}\text { How often do you floss your teeth? } \\
\text { Once or more a day } \\
\text { Occasionally or none }\end{array}$ & $\begin{array}{c}6(3.6 \%) \\
162(96.4 \%)\end{array}$ & $\begin{array}{l}54(23.4 \%) \\
177(76.6 \%)\end{array}$ & $\begin{array}{c}60(15 \%) \\
339(85 \%)\end{array}$ & $.000^{*}$ \\
\hline $\begin{array}{c}\text { How often do use mouth-rinse? } \\
\text { Once or more a day } \\
\text { Occasionally or none }\end{array}$ & $\begin{array}{l}31(18.5 \%) \\
137(81.6 \%)\end{array}$ & $\begin{array}{l}88(38.1 \%) \\
143(61.9 \%)\end{array}$ & $\begin{array}{l}119(29.8 \%) \\
280(70.2 \%)\end{array}$ & $.000^{*}$ \\
\hline $\begin{array}{c}\text { Do you use fluoridated toothpaste? } \\
\text { Yes } \\
\text { No } \\
\text { Don't know }\end{array}$ & $\begin{array}{l}71(42.3 \%) \\
19(11.3 \%) \\
78(46.4 \%)\end{array}$ & $\begin{array}{l}162(72.7 \%) \\
16(4.3 \%) \\
53(22.9 \%)\end{array}$ & $\begin{array}{c}233(58.4 \%) \\
35(8.7 \%) \\
131(32.9 \%)\end{array}$ & $.000^{*}$ \\
\hline
\end{tabular}


(Table 3) contd.....

\begin{tabular}{|c|c|c|c|c|}
\hline Variable & Visually Impaired N (\%) & Control N (\%) & Total N (\%) & $P$-Value \\
\hline $\begin{array}{c}\text { Frequency of eating sweets } \\
\text { Once or more a day } \\
\text { Occasionally }\end{array}$ & $\begin{array}{c}140(83.3 \%) \\
28(16.7 \%\end{array}$ & $\begin{array}{c}205(88.7 \%) \\
26(11.3 \%)\end{array}$ & $\begin{array}{c}345(86.5 \%) \\
54(13.5 \%)\end{array}$ & .474 \\
\hline $\begin{array}{c}\text { Frequency of drinking soda/day } \\
1-2 \text { cans } \\
3-4 \text { cans } \\
\text { None }\end{array}$ & $\begin{array}{c}157(93.4 \%) \\
7(4.2 \%) \\
4(2.4 \%)\end{array}$ & $\begin{array}{c}211(91.3 \%) \\
12(5.2 \%) \\
8(3.5 \%)\end{array}$ & $\begin{array}{c}368(92.2 \%) \\
19(4.7 \%) \\
12(3.1 \%)\end{array}$ & $.005^{*}$ \\
\hline
\end{tabular}

*Significant result, $(P<.05)$ Chi-square test.

According to the main reason for the last visit to a dental clinic, results disclosed that toothache was the main reason as reported by both visually impaired and control groups, being $53.2 \%$ and $61.9 \%$, respectively. Furthermore, results revealed that only $15 \%$ of the control participants visited a dental clinic for a check-up, while none of the visually impaired participants visited dental clinic (Fig. 1).

Table 4 displays the common barriers that may impede access to dental services by persons involved in the current study. Public issues like long waiting time, high cost or the absence of any insurance displayed no significant difference between individuals in both groups $(\mathrm{P}>0.05)$. Whilst, other barriers like; embarrassment (22\%), lack of knowledge of how to treat disabled dental patients $(12.5 \%)$, and inadequate facilities $(13.7 \%)$ are significantly $(\mathrm{P}<0.05)$ higher among patients with a visual impairment than the control. Interestingly, results highlighted that significantly fewer visually impaired participants considered fear as a barrier to visiting dental clinics than the sighted participant.

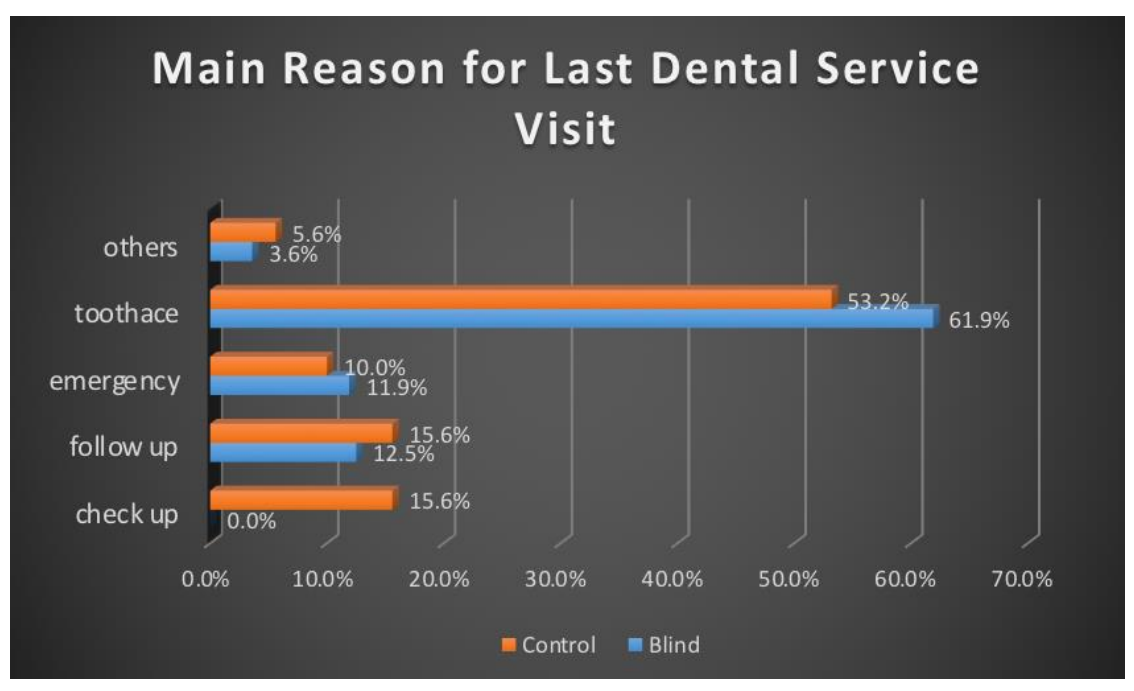

Fig. (1). Reasons for last dental visit for individuals with vision impairment and control participants.

Table 4. Barriers to access to dental services among visually impaired participants and control group.

\begin{tabular}{|c|c|c|c|c|}
\hline Barrier & Visually Impaired N (\%) & Control N (\%) & Total N (\%) & $P$-value \\
\hline Could not afford the cost & $48(50.0)$ & $99(42.9)$ & $147(36.8 \%)$ & .270 \\
\hline Dental office is too far away & $37(22.0)$ & $55(23.8)$ & $92(23.0 \%)$ & .600 \\
\hline Dental office is not open at convenient times & $27(16.1)$ & $74(32.0)$ & $101(25.3 \%)$ & $.000^{*}$ \\
\hline Dental office has no or difficult access for wheelchair & $26(15.5)$ & $44(19.1)$ & $70(17.5 \%)$ & .354 \\
\hline Dental office has inaccessible parking areas & $28(16.7)$ & $14(6.1)$ & $42(10.5 \%)$ & $.001^{*}$ \\
\hline Dental office has small space & $26(15.5)$ & $9(3.9)$ & $35(8.7 \%)$ & $.000^{*}$ \\
\hline Dental office has inadequate facilities to provide dental care & $23(13.7)$ & $8(3.5)$ & $31(7.8 \%)$ & $.000 *$ \\
\hline Dentist lack of knowledge of how to treat people with disability & $21(12.5)$ & $12(5.2)$ & $33(8.3 \%)$ & $.023^{*}$ \\
\hline Dental office has a general dentist not a specialist & $24(14.3)$ & $44(19.0)$ & $68(17 \%)$ & .212 \\
\hline Long waiting time & $72(42.9)$ & $113(48.9)$ & $185(46 \%)$ & .231 \\
\hline Fear of dental work & $58(34.5)$ & $138(59.7)$ & $196(49.1 \%)$ & $.000 *$ \\
\hline No Insurance coverage/dental coverage & $64(38.1)$ & $96(41.6)$ & $160(40.1 \%)$ & .486 \\
\hline Embarrassment or any psychological barriers & $37(22.0)$ & $21(9.1)$ & $58(14.5 \%)$ & $.000^{*}$ \\
\hline
\end{tabular}




\section{DISCUSSION}

Both genders were represented comparatively in the current study. This is not in line with other studies carried out in countries that share similar conservative cultural believes which tend to be overprotective to females $[4,6]$. The findings also disagree with a study carried out in Taiwan, where gender differences were in favor of males, which was attributed to culture specific factors as parents prefer sending their daughters to go to nearby schools [16].

The current study indicated significant differences between the visually impaired and sighted subjects, which reflects a dissimilar level of oral health knowledge and awareness. These findings agree with previous studies that indicated that sighted students were more knowledgeable about dental health than their visually impaired counterparts [3, 16, 17] and that individuals with visual impairment received less information regarding oral health in a proper format appropriate to their visual loss $[9,18]$. Although, visually impaired and sighted participants were equally knowledgeable about the role of bacteria in developing carious lesions, the visually impaired outperformed the sighted participants regarding the use of dental floss. This result was in disagreement with previous studies [3, 16]. It was also observed that a higher percentage of "Don't know" answers were mostly recorded for visually impaired participants, which indicates a lacking in the delivery of oral health information to this group of the population.

Apparently, the visually impaired participants can acquire some knowledge if delivered in an appropriate format. Nevertheless, contrary to sighted participants, the visually impaired participants could not be insightful enough about gum bleeding as an abnormal sign of healthy gingiva. This sign is not detectable by visually impaired subjects because the visual channel is the most effective way to identify this condition [16]. It should also be noted that a person suffering from a visual disability, despite being in the society, can be less concerned about oral health [3]. Despite the reported differences, the majority of both groups believed that soft drinks negatively affect dental health. This information is commonly publicized through media and thus can be expected to be accessed by visually impaired and sighted subjects alike.

The findings clearly outlined a significant gap in oral health knowledge between sighted and visually impaired participants in the current study. Sighted individuals surpassed their visually impaired counterparts in the majority of knowledge items explored. This could be partially attributed to the difficulty encountered by visually impaired participants to visualize and thus appreciate the importance of their oral health. Another possible explanation can be related to the fact that the sighted participants had a higher level of tertiary education compared to the visually impaired participants.

Concerning the oral hygiene practices, the results of the current study indicate statistical differences between the two groups. Sighted participants surpassed their visually impaired counterparts on the frequency of tooth brushing. This is not in line with the findings of Chang and Shih, [6], who reported non-significant differences between similar groups of participants. Though, a similar percentage of tooth brushing frequency amongst visually impaired individuals of similar age group was previously reported. [6] Unlike sighted individuals, approximately one-third of visually impaired individuals needed help or were completely reliant on caregivers in brushing their teeth. Thus, the frequency of tooth brushing amongst visually impaired participants is markedly dependent on the compliance of their caregivers in providing daily assistance in brushing their sibling's teeth. This was confirmed in a previous study [19]. The family seems to have the greatest impact on educating visually impaired subjects [6]. It has been noted that teaching tooth brushing using special aids can improve the manual dexterity of visually impaired students and allow them to be more in control of their tooth brushing. [3 - 4, 20]

The sighted participants also surpassed their visually impaired counterparts on the frequency of usage of mouth-rinse and fluoridated toothpaste. The latter could be related to a lack of knowledge and inability to accurately report whether the toothpaste used is fluoridated or not. Despite the higher percentage of the use of mouth-rinse, only $38 \%$ of the sighted participants regularly used it. Further education is obviously needed to raise the awareness of both groups regarding the benefits of regular use of mouth rinse, with special emphasis on the visually impaired.

Despite the good level of knowledge of the visually impaired people about the importance of dental floss, only $3.6 \%$ used it regularly. These findings corroborated previous results. $[3,16,21]$ This clearly demonstrates the gap between knowledge and practice. It can be inferred that the visually impaired participants could not practice dental flossing, probably due to lack of adequate training and education or inadequate assistance given by caregivers. This indicates the need to reinforce and encourage the daily use of this oral hygiene device and also emphasizes the need to teach the appropriate method for its use in both groups. Specially designed training programs employing appropriate audio-visual communication tools proved efficient in improving brushing technique, frequency and oral hygiene measure effectively $[22$, 23].

Despite the great knowledge of sighted participants regarding the correlation between sugary food and beverages consumption and the development of tooth decay, on practice level, both groups were not significantly different regarding the frequency of consuming sugary food and drinking carbonated drinks. These results agree with that of Vigild et al. [21], and Chang and Shih [16], who reported high consumption of sugary food by adolescents in Kuwait and Thailand, respectively. These findings indicate the need to establish oral health education programs with special attention to deliver more dietary instructions to enhance dental health [3, 24, 25].

While a minority of sighted participants visited the dentist regularly for a routine checkup, none of the sighted participants did so. Regular dental visits have been associated with a reduced incidence of caries [26, 27]. The current findings are in accordance with previous reports [16, 18, 28, 29]. Moreover, more sighted participants reported that the reason for the last visit to the dentist was toothache compared to visually impaired subjects. Obviously, pain is the main reason for 
seeking professional dental treatment. This agrees with a previous study that found visually impaired elderly, although more likely to clean their teeth than their sighted peers, but are more likely to have a tooth extracted than restored. [9] This may suggest difficulties in delivering the appropriate information about the treatment of dental disease. It also may reflect the unavailability of timely assistance of visually impaired individuals, as due to lack of their full autonomy, they mostly require an escort to attend multi-appointment dental treatments.

The current investigation has also attempted to explore the potential obstacles to convenient accessibility of both groups to dental services. Accessibility is understood as the product of the interaction between effective availability of health services and factors that affect the individuals' access to these services [30]. The potential vulnerability of visually impaired individuals is aggravated because the incidence of caries and periodontal disease in people with visual impairment could be higher than in the general population [31, 32].

It has been noted that some potential barriers to access dental services were perceived equally by both groups. On the other hand, a significantly higher percentage of visually impaired participants considered the lack of appropriate facilities in the dental office and lack of adequate competency and knowledge of the dentist in treating people with disability as potential barriers to receiving dental care. This agrees with a previous study by Leal Rocha and co-workers [30], in which dentists reported not to be qualified enough to work with people with special needs. Thus, the need for specialized training on providing care to special patients is considered essential [30].

The visually impaired participants also perceived feeling of embarrassment as a highly significant barrier compared to sighted counterparts. This is in accordance with a previous study that found a positive relationship between psychophysiological disorders and anxiety, frustration, aggression and adjustment among visually impaired students [33]. This is most likely explained by poor adjustment of visually impaired participants with the surrounding environment and not being able to receive social stimuli effectively to feel comfortable with people. It is also probably explained by the cultural attitude of society towards visually impaired people and how this can ease or accentuate the impact of their disability.

It is surprising that significantly more sighted participants considered fear as a barrier towards seeking dental treatment. Fear and anxiety toward the dentist and dental treatment are both significant characteristics that contribute to the avoidance of dental care [34]. The difference between the two groups cannot be easily explained. Probably the inability of visually impaired participants to visualize dental instruments that may provoke anxiety and fear, such as injection needles and burs has lessened their sensation of fear from dental treatment. It is imperative that access to dental services for this population should be facilitated, taking into account the limiting factors, their health and social needs.

Despite the valuable information gathered, the current study suffers from few limitations. Selection bias is one limitation of the study as those not registered at school or centers and raised at home were not included in this study. In addition, this study was based on information collected by selfreported questionnaires, with answers based on respondents' subjective interpretation, which may be biased.

\section{CONCLUSION}

Visually impaired adolescents in Jordan were significantly less knowledgeable about different oral health aspects than sighted counterparts. Moreover, visually impaired individuals used toothbrush, dental floss and mouth rinse less frequently. They also visited dentists less regularly and mostly when only feeling pain. Furthermore, the visually impaired reported that they had limited access to dental services compared to sighted individuals.

\section{ETHICS APPROVAL AND CONSENT TO PARTI- CIPATE}

The study protocol was approved by the Jordan University of Science and Technology (JUST) Institutional Review Board, Jordan, with protocol number 2017/0032).

\section{HUMAN AND ANIMAL RIGHTS}

No animals were used in this research. All human research procedures followed were in full accordance with the ethical standards of the committee responsible for human experimentation (institutional and national), and with the World Medical Association Declaration of Helsinki of 1975, as revised in 2008.

\section{CONSENT FOR PUBLICATION}

Informed consent was obtained from all subjects and from parents and/or legal guardians of minors in the study.

\section{AVAILABILITY OF DATA AND MATERIALS}

The datasets generated and analyzed during the current study are not publicly available due to information that could compromise the privacy of research participants but can be made available on reasonable request to the corresponding author [S.A].

\section{FUNDING}

This study was funded by the Deanship of Research, Jordan University of Science and Technology, Grant Number (0032).

\section{CONFLICT OF INTEREST}

The authors declare no conflict of interest, financial or otherwise.

\section{ACKNOWLEDGEMENTS}

Declared none.

\section{REFERENCES}

[1] Allison PJ, Hennequin M, Faulks D. Dental care access among individuals with down syndrome in France. Spec Care Dentist 2000; 20(1): 28-34.

[http://dx.doi.org/10.1111/j.1754-4505.2000.tb00007.x] [PMID: 11203873]

[2] Kenney MK, Kogan MD, Crall JJ. Parental perceptions of dental/oral health among children with and without special health care needs. 
Ambul Pediatr 2008; 8(5): 312-20.

[http://dx.doi.org/10.1016/j.ambp.2008.04.005] [PMID: 18922505]

[3] Debnath A, Srivastava BK, Shetty P, Eshwar S. New vision for improving the oral health education of visually impaired children- A non randomized control trial. J Clin Diagn Res 2017; 11(7): ZC29-32. [http://dx.doi.org/10.7860/JCDR/2017/26515.10170] [PMID: 28893038]

[4] Dorout IA, Tobaigy FM, Al Moaleem MM, Ahmad M, Shubayr MA, Kinani HM. Knowledge and oral health related behavior among visually impaired subjects in Jazan region, Kingdome of Saudi Arabia. J Dent Oral Hyg 2015; 7: 33-9.

[http://dx.doi.org/10.5897/JDOH2014.0136]

[5] Parkar SM, Patel N, Zinzuwadia H. Dental health status of visually impaired individuals 405attending special school for blind in Ahmedabad city, India Indian J Oral Sci 2014; 5: 73. [http://dx.doi.org/10.4103/0976-6944.136843]

[6] Ali SH, Hamad AM, Zardawi FM, Arif AN. Oral health knowledge, practice and oral 408 hygiene status amongst visually impaired students in Sulaimani city/Iraq OSR J Dent Med 409Sci (IOSR-JDMS) 2015; 14: $62-8$.

[http://dx.doi.org/10.9790/0853-14966268]

[7] Cunha LD, Proença MA, Rodrigues VP, Pereira AFV, Benatti BB. Relationship between periodontal status and degree of visual impairment in institutionalized individuals. Eur J Dent 2015; 9: 324. [http://dx.doi.org/10.4103/1305-7456.163322]

[8] Mohan R, Raju R, Gubbihal R, Kousalya PS. Comprehensive dental care for the visually impaired: A review. Int J Oral Health Med Res 2016; 3: 97-101

[http://dx.doi.org/10.15406/jdhodt.2018.09.00382]

[9] Watson EK, Moles DR, Kumar N, Porter SR. The oral health status of adults with a 417 visual impairment, their dental care and oral health information needs $\mathrm{Br}$ Dent J 2010; 208: 1-6.6.doi.org/10.1038/sj.bdj.2010.395

[10] Ministry of Health in Jordan (MOH). National Prevalence Study for Blindness and Low 420Vision, Jordan 2008. Available from: http://apps.moh.gov.jo

[11] The World Medical Association. WMA declaration of helsinki ethical principles for 422 medical research involving human subjects adopted by the 18th WMA general 423 assembly, Helsinki, Finland 1964. Available from: https://www.wma.net/policies-post/wma-declaration-of-helsinki-ethica 1-principles-for-medical-research-involving-human-subjects

[12] Ministry of Social Development. Available from: http://www.mosd.gov.jo/UI/Arabic/Default.aspx

[13] Ministry of Education. Available from: http://www.moe.gov.jo/en/node/19404

[14] Papadopoulos K, Papakonstantinou D, Montgomery A, Solomou A. Social support and depression of adults with visual impairments. Res Dev Disabil 2014; 35(7): 1734-41.

[http://dx.doi.org/10.1016/j.ridd.2014.02.019] [PMID: 24679546]

[15] Nyman SR, Dibb B, Victor CR, Gosney MA. Emotional well-being and adjustment to vision loss in later life: a meta-synthesis of qualitative studies. Disabil Rehabil 2012; 34(12): 971-81. [http://dx.doi.org/10.3109/09638288.2011.626487] [PMID: 22066708]

[16] Chang C, Shih Y. Knowledge of dental health and oral hygiene practices of Taiwanese visually impaired and sighted students. J Vis Impair Blind 2004; 98: 289-303.

[http://dx.doi.org/10.1177/0145482X0409800504]

[17] Anaise JZ. Periodontal disease and oral hygiene in a group of blind and sighted Israeli teenagers (14--17 years of age. Community Dent Oral Epidemiol 1979; 7(6): 353-6.

[http://dx.doi.org/10.1111/j.1600-0528.1979.tb01247.x] [PMID: 295720]

[18] AlSadhan SA, Al-Jobair AM, Bafaqeeh M, Abusharifa H, Alagla M. Dental and medical health status and oral health knowledge among visually impaired and sighted female schoolchildren in Riyadh: a comparative study. BMC Oral Health 2017; 17(1): 154.

[http://dx.doi.org/10.1186/s12903-017-0446-6] [PMID: 29258491]

[19] Jain A, Gupta J, Aggarwal V, Goyal C. To evaluate the comparative status of oral health practices, oral hygiene and periodontal status amongst visually impaired and sighted students. Spec Care Dentist 2013; 33(2): 78-84.

[http://dx.doi.org/10.1111/j.1754-4505.2012.00296.x] [PMID: 23451928]

[20] Shih YH, Chang CS. Teaching oral hygiene skills to elementary students with visual impairments. J Vis Impar and blind. 2005; impairments. J Vis Impair Blind 2005; 99: 1-28.

[http://dx.doi.org/10.1177/0145482X0509900104]

[21] Vigild M, Petersen PE, Hadi R. Oral health behaviour of 12-year-old children in Kuwait. Int J Paediatr Dent 1999; 9(1): 23-9. [http://dx.doi.org/10.1046/j.1365-263x.1999.00097.x]

[PMID: 10336713]

[22] Joybell C, Krishnan R, v SK. Comparison of two brushing methodsfone's vs modified bass method in visually impaired children using the audio tactile performance (ATP) technique. J Clin Diagn Res 2015; 9(3): ZC19-22.

[http://dx.doi.org/10.7860/JCDR/2015/11307.5651]

[PMID: 25954698]

[23] Gautam A, Bhambal A, Moghe S. Effect of oral health education by audio aids, Braille \& tactile models on the oral health status of visually impaired children of Bhopal city. J Oral Biol Craniofac Res 2018; 8(3): 168-70.

[http://dx.doi.org/10.1016/j.jobcr.2017.03.002] [PMID: 30191102]

[24] Moynihan PJ. Dietary advice in dental practice. Br Dent J 2002; 193(10): 563-8

[http://dx.doi.org/10.1038/sj.bdj.4801628] [PMID: 12481178]

[25] Yalcinkaya SE, Atalay T. Improvement of oral health knowledge in a group of visually impaired students. Oral Health Prev Dent 2006; 4(4): 243-53.

[PMID: 17153646]

[26] Van Nieuwenhuysen JP, Carvalho JC, D'Hoore W. Caries reduction in belgian 12-year-old children related to socioeconomic status. Acta Odontol Scand 2002; 60(2): 123-8.

[http://dx.doi.org/10.1080/000163502753509545] [PMID: 12020116]

[27] Lindemann R, Zaschel-Grob D, Opp S, Lewis MA, Lewis C. Oral health status of adults from a California regional center for developmental disabilities. Spec Care Dentist 2001; 21(1): 9-14. [http://dx.doi.org/10.1111/j.1754-4505.2001.tb00217.x] [PMID: 11795453]

[28] Schembri A, Fiske J. The implications of visual impairment in an elderly population in recognizing oral disease and maintaining oral health. Spec Care Dentist 2001; 21(6): 222-6.

[http://dx.doi.org/10.1111/j.1754-4505.2001.tb00258.x] [PMID: 11885671]

[29] Nandini NS. New insights into improving the oral health of visually impaired children. J Indian Soc Pedod Prev Dent 2003; 21(4): 142-3. [PMID: 14765613]

[30] Leal Rocha L, Vieira de Lima Saintrain M, Pimentel Gomes Fernandes Vieira-Meyer A. Access to dental public services by disabled persons. BMC Oral Health 2015; 15: 35.

[http://dx.doi.org/10.1186/s12903-015-0022-x] [PMID: 25887657]

[31] Liu L, Zhang Y, Wu W, et al. Oral health status among visually impaired schoolchildren in Northeast China. BMC Oral Health 2019; 19(1): 63.

[http://dx.doi.org/10.1186/s12903-019-0752-2] [PMID: 31029116]

[32] Tagelsir A, Khogli AE, Nurelhuda NM. Oral health of visually impaired schoolchildren in Khartoum State, Sudan. BMC Oral Health 2013; 13: 33

[http://dx.doi.org/10.1186/1472-6831-13-33] [PMID: 23866155]

[33] Bhuvaneswari M, Immanuel Selvaraj C, Selvaraj B, Srinivasan T. Assessment of psychological and psycho-physiological problems among visually impaired adolescents. Iran J Psychiatry Behav Sci 2016; 10(1)e3895

[http://dx.doi.org/10.17795/ijpbs-3895] [PMID: 27284280]

[34] Pohjola V, Lahti S, Vehkalahti MM, Tolvanen M, Hausen H. Association between dental fear and dental attendance among adults in Finland. Acta Odontol Scand 2007; 65(4): 224-30. [http://dx.doi.org/10.1080/00016350701373558] [PMID: 17762985] 